\title{
Efektivitas Pelatihan Berpikir Positif untuk Meningkatkan Optimisme pada Anak Binaan di Lembaga Pembinaan Khusus Anak
}

\section{Effectiveness of Positive Thinking Training in Improving Optimism among the juveniles in Juvenile Correctional Institution}

\author{
Leli Nailul Muna, H. Fuad Nashori, Indahria Sulistyarini \\ Program Studi Psikologi Profesi (S2), Fakultas Psikologi dan Ilmu Sosial Budaya, \\ Universitas Islam Indonesia, Yogyakarta \\ Email: fuadnashori@uii.ac.id
}

KATA KUNCI Berpikir Positif, Optimisme, Anak Binaan.

KEYWORDS Positive Thinking, Optimism, Juvenile Deliquency.

ABSTRAK

Penelitian ini bertujuan untuk mengetahui pengaruh pelatihan berpikir positif dalam meningkatkan optimisme pada anak binaan di Lembaga Pembinaan Khusus Anak, Jawa Tengah. Optimisme adalah keyakinan bahwa keyakinan bahwa hal-hal baik akan lebih sering terjadi daripada hal-hal buruk, sehingga individu percaya bahwa sesuatu akan berjalan sesuai dengan harapan. Pelatihan berpikir positif mengacu pada teori ABCDE dari Seligman (2006). Penelitian ini menggunakan metode eksperimen dengan rancangan pretest dan postest yang diterapkan pada kelompok eksperimen dan kelompok kontrol (pretest postest with control group design). Pemilihan subjek penelitian ditetapkan dengan menggunakan metode matching. Subjek penelitian berjumlah 18 anak laki-laki yang berusia 14-17 tahun, dengan sembilan subjek berada di kelompok eksperimen dan sembilan subjek berada di kelompok kontrol. Metode pengumpulan data menggunakan skala optimisme LOT-R dari Scheier, Carver, dan Bridge (1994). Uji hipotesis dilakukan menggunakan analisa data statistik yang menunjukkan bahwa pelatihan berpikir positif secara signifikan meningkatkan optimisme pada kelompok eksperimen, sedangkan kelompok kontrol yang tidak diberikan pelatihan tidak mengalami perubahan skor optimisme. 
ABSTRACT This study aimed to examine the effectiveness of positive thinking training in improving optimism among the juveniles in Class 1 Juvenile Correctional Facility, Central Java. Optimism is the belief that good things will come more often than bad things, making individuals believe that things will go as expected. The positive thinking training refers to the theory of ABCDE from Seligman (2006). This study used an experimental method with the pretest and posttest design applied to an experimental group and a control group (pretest posttest with control group design). The selection of research subjects was determined using the matching method. The subjects consisted of 18 boys aged 14-17 years, with nine subjects in the experimental group and nine subjects in the control group. The data collection method used the LOT-R optimism scale from Scheier, Carver, \& Bridge (1994). The hypothesis testing performed using a statistical data analysis showed that the positive thinking training significantly increased optimism in the experimental group, while the control group that was not given the training did not experience changes in optimism scores.

\section{PENDAHULUAN}

Tindak kejahatan atau kriminalitas yang dilakukan oleh anak menjadi permasalahan yang dihadapi oleh berbagai negara di seluruh dunia. Di Amerika Serikat, tindak kriminal oleh anak meningkat drastis pada pertengahan tahun 1980-an sampai awal tahun 1990-an (National Research Council Institute of Medicine, 2001). Di negara berkembang seperti India, kejahatan oleh remaja terhadap perempuan meningkat $7,2 \%$ di tahun 2016 menjadi 35.849 kasus. Sindonews.com melaporkan pada tahun 2018, di Indonesia ada 1.434 anak yang tersangkut tindak kriminal sebagai pelaku (Yusuf, Mufarida, Purnama, Rochim, 2019), dengan kejahatan seksual menjadi kasus yang paling banyak. Kasus-kasus lainnya di antaranya pencurian, kekerasan fisik, penganiayaan, tawuran, dan pembacokan, seperti yang dilaporkan oleh Kompas.com (Halim, 2019).

Meningkatnya angka anak berhadapan dengan hukum (ABH) seiring dengan jumlah anak yang menjalani pembinaan di Lembaga Pembinaan Khusus Anak
(LPKA). Data dari LPKA Kelas I Kutoarjo Jawa Tengah menunjukkan bahwa pada akhir bulan Juli 2019 terdapat 64 orang anak. Berbagai pasal pelanggaran yang dilakukan anak yang berada di LPKA Kelas 1 Kutoarjo diantaranya adalah pasal pencurian sebanyak 17 orang, pencurian disertai kekerasan sebanyak 8 orang, 1 orang pidana pembunuhan berencana, ada 5 anak yang melakukan kekerasan dan penganiayaan terhadap anak, 19 orang melakukan pidana persetubuhan, dan 9 orang melakukan pidana pencabulan (Data Registrasi LPKA Kutoarjo, 2019).

Berhadapan dengan hukum sebagai seorang narapidana tentu bukanlah hal yang mudah, terutama bagi anak yang masih belum memasuki masa dewasa. Anak seharusnya berada di rumah dalam pengawasan dan perlindungan keluarga, bersosialisasi dengan teman, mendapatkan pendidikan yang layak, dan mengembangkan bakat serta minat. Akan tetapi, hal ini tidak didapatkan oleh anak yang menjalani masa pidana di LPKA. Beberapa penelitian terhadap anak di LPKA menemukan bahwa anak mengalami 
berbagai masalah psikologis selama di LPKA, di antaranya stres yang tinggi (Ariyanto, 2016), rasa rindu terhadap keluarga, jenuh dengan aktivitas di LPKA, dan muncul masalah dengan teman sesama anak (Sholichatun, 2011), sulit menyesuaikan diri (Sopiah, Krisnatuti, \& Simanjuntak, 2017), merasa malu, menilai diri negatif, dan sulit menerima keadaan diri (Hilman \& Indrawati, 2017), menghadapi kecemasan menjelang masa bebas (Zulni \& Koentjoro, 2017), serta adanya ide untuk bunuh diri (Shagufta, Boduszek, Dhingra, \& Palmer, 2015).

Anak binaan juga memiliki kekhawatiran mengenai masa depan setelah keluar dari LPKA. Anak merasa bingung dengan apa yang akan mereka lakukan setelah bebas. Anak cenderung merasa putus asa dan pesimis mengenai kondisinya (Sholichatun, 2011). Anak-anak di LPKA membutuhkan motivasi untuk menggapai cita-cita dan menumbuhkan keberanian kembali ke masyarakat setelah keluar (Aulia, 2017). Berdasarkan wawancara peneliti dengan 8 orang anak di LPKA Kutoarjo pada 2019, nampak bahwa beberapa anak merasa tidak optimis dengan masa depannya. Optimisme adalah keyakinan bahwa sesuatu dapat berjalan sesuai dengan harapan dan percaya bahwa sesuatu yang baik akan terjadi daripada sesuatu yang buruk. Sebaliknya, pesimisme adalah keyakinan bahwa sesuatu tidak akan berjalan sesuai dengan harapan, sehingga individu cenderung khawatir dengan masa depan (Scheier \& Carver, 1985).

Berdasarkan hasil wawancara, empat orang responden tidak memiliki tujuan setelah bebas nanti. Seorang responden berinisial D (perempuan, 14 tahun) merasa sangat bingung dan khawatir dengan kondisinya ketika bebas nanti. D tidak memiliki orangtua dan selama ini tinggal di jalanan. D tidak memiliki tujuan untuk tinggal di mana dan melakukan apa setelah keluar nanti. D merasa sangat sedih dan menyesal dengan kondisinya. Responden W (laki-laki, 17 tahun) juga merasa bahwa kasus hukum yang menjeratnya membuat hidup dan masa depannya hancur. W yakin setelah keluar nanti, W akan kesulitan mencari pekerjaan dengan statusnya yang pernah berhadapan dengan hukum. W juga yakin bahwa orang lain akan mempunyai stigma negatif dengan status W (Wawancara, 15 Agustus 2019).

Responen R (laki-laki, 15 tahun) yang akan bebas dalam dua bulan setelah wawancara juga belum memiliki rencana tentang hidupnya setelah bebas. Selain itu, responden I (laki-laki, 15 tahun) juga merasa pesimis karena masa pembinaannya yang masih lama. I merasa bahwa waktu sangat lambat berjalan. I masih belum memikirkan rencananya ke depan nanti. I merasa bahwa masa depannya menjadi suram karena teribat kasus hukum (Wawancara, 30 Juli 2019). Hal ini menunjukkan bahwa beberapa responden tidak memiliki tujuan setelah bebas nanti, padahal tujuan merupakan bagian dari optimisme menurut Scheier dan Carver (Synder \& Lopez, 2002).

Para responden juga cenderung tidak memiliki harapan terhadap masa depannya. Selain tujuan, harapan juga menjadi bagian penting dalam optimisme. Harapan adalah keyakinan akan kemampuan diri dalam mencapai tujuan yang telah ditetapkan (Synder \& Lopez, 2002). Para responden mengatakan bahwa mereka tidak yakin dapat meneruskan pendidikan setelah keluar dari Lembaga Pembinaan. Mereka pernah memiliki cita-cita, namun saat ini cita-cita tersebut telah pupus. Mereka tidak yakin dan tidak memiliki harapan bahwa mereka mampu mewujudkan cita-cita tersebut. Mereka juga tidak yakin bahwa mereka dapat memperbaiki masa depan mereka. Para responden juga merasa bahwa hal-hal baik jarang terjadi pada mereka.

Optimisme merupakan hal yang penting dimiliki oleh anak untuk menghadapi permasalahan yang mereka alami di LPKA. Optimisme memberikan pengaruh positif bagi narapidana yang akan menghadapi masa bebas. Narapidana yang 
lebih optimis lebih mampu menghadapi stigma sosial terhadap status residivis dan memiliki fungsi mental yang lebih baik (Moore, Stuewig, \& Tangney, 2016). Optimisme yang rendah disebabkan adanya keyakinan negatif tentang diri yang didasari oleh pola berpikir yang salah (Nurindah, Afiatin, \& Sulistyarini, 2012). Menurut Scheier dan Carver (dalam Synder \& Lopez, 2002), salah satu faktor yang mempengaruhi optimisme adalah faktor kognitif. Keyakinan dan pikiran yang positif akan meningkatkan optimisme dan membuat individu memandang dirinya dan dunia dengan lebih positif.

Peterson (2000) dalam penelitiannya menjelaskan bahwa optimisme terhadap masa depan dipengaruhi oleh berpikir positif. Berpikir positif adalah cara berpikir yang memandang positif kehidupan. Individu yang berpikir positif memaknai diri, lingkungan, dan situasi sebagai sesuatu yang positif (Seligman, 2006).

Faktor pandangan positif terhadap masa depan merupakan salah satu hal penting yang membuat anak mampu melewati masa tahanan dengan lebih baik. Pandangan positif terhadap masa depan akan membuat anak lebih optimis, mampu menetapkan tujuan, dan memiliki harapan untuk dapat menggapainya. Berpikir positif sangat mempengaruhi kondisi narapida dalam melalui masa tahanan dan menghadapi masa bebas. Berpikir positif membuat narapidana dapat melalui masa tahanan dengan baik, tidak hanya sekedar menunggu waktu untuk keluar. Pikiran positif menuntun narapidana untuk menciptakan dan mencari peluang agar situasi mereka menjadi lebih baik. Situasi yang lebih baik akan mengurangi peluang narapidana mengulangi kriminalitas yang pernah mereka lakukan (Ginneken, 2015).

Penelitian Zulni dan Koentjoro (2017) menunjukkan bahwa pelatihan berpikir positif efektif menurunkan kecemasan menghadapi masa bebas pada anak di LPKA Kutoarjo baik secara kognitif, emosi, fisiologis, serta perilaku. Pelatihan berpikir positif dapat mengubah persepsi dan penilaian peserta mengenai masa depan menjadi lebih positif. Persepsi yang lebih positif terhadap masa depan akan membuat anak lebih optimis, sehingga anak yakin bahwa mereka mencapai harapan-harapan dan tujuan mereka. Beberapa penelitian sebelumnya juga menemukan bahwa pelatihan berpikir positif mampu meningkatkan optimisme. Hasil penelitian Nurindah, Afiatin, dan Sulistyarini (2012) menunjukkan bahwa pelatihan berpikir positif meningkatkan optimisme remaja berusia 13 sampai 18 tahun yang tinggal di panti asuhan.

Penelitian lainnya menunjukkan bahwa teknik konseling ABCDE Seligman juga mampu meningkatkan optimisme pada mahasiswa yang pindah jurusan (Munawaroh, Isrofin, \& Sutikno, 2018). Mahasiswa yang pindah jurusan mengalami kegagalan akademik yang membuat mereka cenderung pesimis. Penelitian Tatara (2017) menunjukkan bahwa pelatihan berpikir positif mampu meningkatkan optimisme penyalahguna narkotika di Balai Rehabilitasi BNN (Badan Nasional Anti Narkoba). Pelatihan ini membantu penyalahguna narkotika untuk mengubah pikiran negatif mereka yang membuat mereka cenderung pesimis menjadi lebih optimis.

Manfaat berpikir positif bagi anak yang menjalani masa pembinaan di LPKA adalah untuk mengubah pola pikir maladaptif menjadi lebih positif. Anak binaan yang memiliki pola pikir yang adaptif akan mampu mengelola perasaannya dan mengontrol perilakunya. Mampu mengelola perasaan dan mengontrol perilaku merupakan hal yang penting agar anak binaan tidak mengulangi perbuatannya dimasa depan. Selain itu, dengan memiliki pola pikir yang positif akan membuat anak lebih mudah mengikuti serta menjalani aktivitas-aktivitas di dalam LPKA, sehingga pembinaan yang diberikan oleh pihak LPKA pun akan memberikan dampak 
yang positif bagi anak, terutama saat anak menghadapi masa bebasnya.

Berdasarkan penjelasan di atas, peneliti tertarik untuk melakukan penelitian mengenai intervensi pelatihan berpikir positif dalam meningkatkan optimisme pada anak di Lembaga Pembinaan Khusus Anak Kelas I di salah satu kota di Jawa Tengah. Hipotesis dalam penelitian ini adalah pelatihan berpikir positif efektif untuk meningkatkan optimisme anak binaan di lembaga pembinaan khusus anak.

\section{METODE PENELITIAN Pendekatan}

Penelitian ini menggunakan metode eksperimen dengan rancangan pretest dan postest yang diterapkan pada kelompok eksperimen dan kelompok kontrol (pretest postest with control group design). Pemilihan subjek penelitian ditetapkan dengan menggunakan metode matching.

\section{Partisipan}

Beberapa kriteria subjek penelitian adalah, berjenis kelamin laki-laki dengan rentang usia 14-18 tahun, memiliki pendidikan minimal pernah menempuh pendidikan sekolah dasar (SD) dan memahami instruksi, serta subjek penelitian baru pertama kali menjadi anak binaan (bukan residivis). Dalam intervensi ini, subjek yang terlibat sebanyak 18 anak, dengan sembilan subjek berada dalam kelompok eksperimen dan sembilan subjek dalam kelompok kontrol.

\section{Instrumen}

Alat ukur yang digunakan untuk mengukur optimisme anak binaan adalah skala optimisme Life Orientation Test Revised (LOT-R) dari Scheier, Carver dan Bridegs (1994). Peneliti menggunakan skala LOT-R yang digunakan dalam penelitian yang dilakukan oleh Wahid, Larasati, Ayuni, dan Nashori (2018) terhadap anak panti asuhan yang berusia remaja. Uji coba skala ini memperoleh nilai koefisien alpha sebesar 0,81 dan koefisien korelasi item-total bergerak dari 0,4510,588 .

\section{Prosedur Penelitian}

Penelitian ini dilaksanakan dengan menggunakan panduan modul pelatihan berpikir positif. Modul pelatihan berpikir positif yang digunakan oleh peneliti dalam penelitian ini merupakan modifikasi dari modul pelatihan berpikir positif dari penelitian Zulni dan Koentjoro (2017). Modul pelatihan berpikir positif milik Zulni dan Koentjoro (2017) dirancang berdasarkan aspek-aspek berpikir positif dari teori kognitif Ellis, yang dikembangkan oleh Seligman (2006). Model teori ini menggunakan teori A-B-C-D-E, yaitu adversity, belief, consequences, disputation, dan energization.

\section{Teknik Analisis Data}

Analisis data menggunakan uji statistik spss. Uji hipotesis dilakukan menggunakan uji non parametrik karena jumlah subjek penelitian kurang dari 30 subjek. Uji non parametrik yang digunakan adalah uji beda wilcoxon digunakan untuk melihat perbedaan skor optimisme pada masing-masing kelompok setelah perlakuan.

\section{ANALISIS DAN HASIL}

Hipotesis yang diajukan dalam penelitian ini adalah hipotesis satu arah, yakni pelatihan berpikir positif efektif dalam meningkatkan optimisme pada anak binaan di lembaga pembinaan khusus anak. Uji hipotesis dilakukan dengan uji analisis wilcoxon untuk mengetahui signifikansi pengaruh pelatihan berpikir positif pada masing-masing kelompok. Subjek yang dianalisis dalam kelompok eksperimen berjumlah tujuh subjek, dua subjek lainnya tidak dianalisis karena satu subjek memiliki skor ekstrem (layouter), dan satu subjek tidak mengikuti semua sesi pelatihan. 
Gambar 1

Nilai Mean Skor Optimisme Kelompok Eksperimen dan Kelompok Kontrol

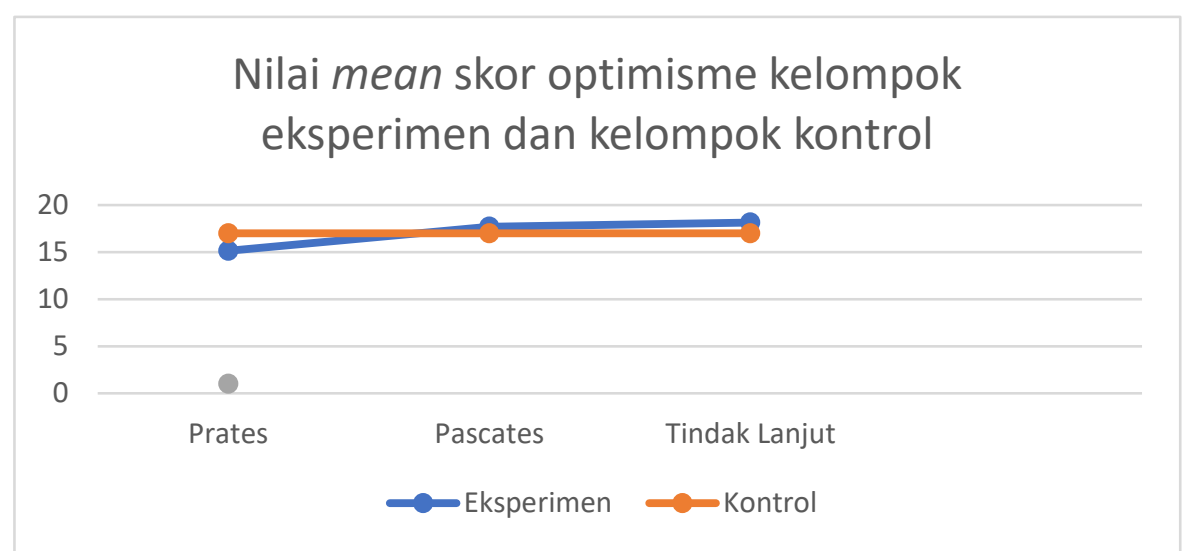

Berdasarkan grafik di atas, dapat dilihat bahwa skor optimisme kelompok eksperimen mengalami peningkatan setelah mengikuti pelatihan berpikir positif. Skor optimisme pada kelompok eksperimen meningkat dari mean $=15,14 ; \mathrm{SD}=1,95$ menjadi mean $=17,71 ; \mathrm{SD}=3,72$. Sedangkan skor optimisme kelompok kontrol tidak mengalami peningkatan dari prates ke paskates, dengan mean $=17 ; \mathrm{SD}=$ 1,11 menjadi mean $=17 ; \mathrm{SD}=3,2$. Pada tindak lanjut, skor mean dari kelompok eksperimen adalah mean $=18,14 ; \mathrm{SD}=$ 2,03, dan pada kelompok kontrol skor optimisme adalah mean $=17 ; \mathrm{SD}=2,64$.

Tabel 1

Uji Hipotesis

\begin{tabular}{|lllll|}
\hline \multirow{2}{*}{ Pengukuran } & \multicolumn{4}{c|}{ Uji beda skor optimisme pada masing-masing kelompok } \\
& \multicolumn{2}{c|}{ Kelompok eksperimen } & \multicolumn{2}{l|}{ Kelompok kontrol } \\
& $\mathrm{Z}$ & $p$ & $\mathrm{Z}$ & $p$ \\
Prates ke pascates & $-1,997$ & 0,023 & $-0,144$ & 0,442 \\
Pascates ke tindak lanjut & $-0,212$ & 0,416 & $-0,070$ & 0,472 \\
Prates ke tindak lanjut & $-2,388$ & 0,008 & $-0,119$ & 0,452 \\
\hline
\end{tabular}


Berdasarkan tabel di atas, pada kelompok eksperimen dapat dilihat ada perbedaaan signifikan antara prates dan pascates dengan nilai $Z=-1,997$ dan nilai $\mathrm{p}=0,023(p<0,05)$. Hal ini berarti terdapat perbedaan skor optimisme yang signifikan pada kelompok eksperimen setelah diberikan pelatihan. Sedangkan pada kelompok kontrol tidak ada perbedaan signifikan antara prates dan pascates dengan nilai $Z=-0,144$ dan nilai $p=0,442$.

\section{DISKUSI}

Tujuan penelitian ini adalah untuk mengetahui pengaruh pelatihan berpikir positif dalam meningkatkan optimisme anak binaan di lembaga pembinaan khusus anak. Berdasarkan hasil penelitian, hipotesis yang diajukan dalam penelitian ini diterima, yaitu bahwa terdapat pengaruh pelatihan berpikir positif dalam meningkatkan optimisme anak binaan. Kelompok eksperimen yang diberikan perlakuan mengalami peningkatan skor optimisme, sedangkan kelompok kontrol yang tidak diberikan perlakuan tidak mengalami peningkatan skor optimisme.

Hasil penelitian ini mendukung pendapat Peale (1996) yang menyatakan bahwa individu yang berpikir positif akan lebih mudah mencapai kesuksesan, optimisme, kemampuan pemecahan masalah, dan menjauhkan diri dari perasaan takut akan kegagalan. Hasil penelitian ini juga sejalan dengan penelitian Peterson (2000) yang menemukan bahwa berpikir positif mempengaruhi optimisme terhadap masa depan.

Beberapa penelitian sebelumnya juga menemukan bahwa pelatihan berpikir positif mampu meningkatkan optimisme, di antaranya penelitian Nurindah, Afiatin, dan Sulistyarini (2012) yang menemukan bahwa pelatihan berpikir positif meningkatkan optimisme remaja yang tinggal di panti asuhan. Penelitian lain juga menemukan bahwa teknik konseling ABCDE Seligman mampu meningkatkan optimisme pada mahasiswa yang pindah jurusan (Munawaroh, Isrofin, \& Sutikno, 2018). Hasil penelitian Tatara (2017) juga menunjukkan bahwa pelatihan berpikir positif mampu meningkatkan optimisme penyalahguna narkotika di Balai Rehabilitasi Badan Narkotika Nasional (BNN). Pelatihan berpikir positif membantu penyalahguna narkotika untuk mengubah pikiran negatif yang pesimis menjadi lebih optimis.

Dalam pelatihan berpikir positif yang peneliti lakukan, para peserta berlatih untuk mengenali peristiwa buruk yang sudah mereka lalui, pikiran atau keyakinan negatif, serta konsekuensi dari hal-hal tersebut. Selama proses mengidentifkasi peristiwa buruk, peserta belajar untuk membedakan peristiwa buruk yang menjadi tanggung jawab mereka dan bisa mereka ubah, serta peristiwa buruk yang terjadi diluar kendali diri mereka dan tidak dapat mereka ubah.

Mayoritas peserta menulis peristiwa buruk yang mereka alami adalah peristiwa yang menjadi kesalahan mereka seperti mabuk-mabukan, menggunakan obatobatan terlarang, tawuran, mencuri, dan menonton video porno. Dalam proses ini peserta juga belajar memahami bahwa peristiwa buruk yang mereka lakukan merupakan tanggung jawab mereka. Penelitian Nwokeoma dkk. (2019) menunjukkan bahwa perubahan kognitif membantu narapidana memiliki keterampilan berpikir sebelum bertindak, memahami konsekuensi, dan mengembangkan mekanisme mengontrol diri.

Tahap berikutnya dalam pelatihan berpikir positif adalah peserta mengidentifikasi pikiran atau keyakinan negatif yang mereka miliki. Peserta menuliskan pikiran atau keyakinan negatif berkaitan dengan peristiwa buruk yang terjadi. Mayoritas peserta berpikir bahwa mereka akan ditolak oleh keluarga, ditolak oleh lingkungan, dan ditolak oleh temanteman ketika bebas nanti. Para peserta juga merasa tidak yakin dengan diri mereka 
sendiri. Mereka khawatir jika mereka tetap melakukan hal yang sama ketika bebas nanti. Pikiran-pikiran negatif yang dimiliki para peserta membawa mereka kepada rasa pesimis terhadap masa depan mereka. Para peserta tidak yakin bahwa mereka bisa merubah masa depan dan memiliki masa depan yang lebih baik. Mengidentifikasi pikiran-pikiran atau keyakinan negatif merupakan tahap penting dalam proses merekonstruksi kognitif (Blattman, Jamison, \& Sheridan, 2017).

Selama pelatihan berpikir positif, peserta merasa bebas untuk mengutarakan kekhawatiran dan ketakutan yang mereka rasakan. Hal ini membantu para peserta untuk mampu mengenal dan mengidentifikasi perasaan yang mereka rasakan. Keterampilan untuk mengenal perasaan merupakan salah satu bagian dari keterampilan regulasi emosi. Kemampuan regulasi emosi negatif dibutuhkan oleh anak binaan agar mereka tidak mudah dikuasai rasa marah atau rasa tersinggung. Kemampuan regulasi emosi berkontribusi dalam mencegah perilaku impulsif dan menurunkan kecenderungan kecemasan serta depresi pada anak lapas (Mestre, Vidal, \& Garcia, 2017).

Pada tahap pelatihan berpikir positif selanjutnya, yakni tahap menentang pikiran negatif, para peserta diajarkan beberapa teknik yang dapat dilakukan untuk mengubah pikiran atau keyakinan negatif yang mereka miliki. Beberapa peserta menemukan alternatif mengalihkan pikiran negatif mengenai diri dan masa depan mereka dengan melakukan aktivitasaktivitas bermanfaat di LPKA seperti beribadah, berdoa, mengikuti pelatihan dan kerja selama di LPKA. Menurut penelitian Ginneken (2015), narapidana yang optimis dengan masa depan akan menjalani masa pidana dengan lebih baik dan mempersiapkan diri sebelum bebas dibandingkan dengan narapidana yang pesimis.

Selanjutnya pada tahap menentang pikiran negatif, beberapa peserta juga mampu menentang pikiran negatifnya dan menemukan alternatif pikiran yang lebih positif, misalnya seperti keluarga mereka akan selalu menerima mereka sehingga mereka tidak perlu khawatir akan ditolak oleh keluarga, atau mereka dapat menemukan teman-teman yang lebih baik jika teman-teman mereka yang dulu meninggalkan mereka ketika mereka sudah keluar. Memiliki dukungan sosial terutama dukungan dari keluarga merupakan hal yang sangat penting bagi anak binaan. Penelitian menunjukkan bahwa kunjungan keluarga membantu individu mempertahankan ikatan sosial selama berada di penjara, yang, pada gilirannya, dapat meningkatkan perilaku sosial narapidana dan mengurangi kecenderungan residivisme (Cochran, Mears, \& Bales, 2014).

Para peserta juga belajar untuk memahami konsekuensi mengenai perilaku mereka dan memisahkan hal tersebut dengan keyakinan dasar negatif mengenai diri mereka. Melalui pelatihan berpikir positif, para peserta memahami bahwa perbuatan mereka salah dan keberadaan mereka di LPKA merupakan bentuk pertanggung jawaban yang mereka lakukan untuk menebus kesalahan mereka. Jika mereka mampu menerima hukuman tersebut berarti mereka mampu bertanggung jawab. Para peserta juga memahami bahwa kesalahan yang mereka lakukan tidak berarti menjadikan mereka anak yang tidak berharga dan sia-sia. Para peserta memahami bahwa mereka memiliki kesempatan untuk berubah dan memiliki masa depan yang sama dengan anak-anak lainnya.

Keyakinan positif mengenai diri dan masa depan yang dilatih dalam pelatihan berpikir positif memberikan dampak terhadap optimisme para peserta. Setelah mengikuti pelatihan, para peserta mengalami kenaikan skor pada aspek optimisme. Harapan para peserta mengenai masa depan akan menjadi lebih baik semakin meningkat. Selain itu, para peserta 
menjadi semakin yakin bahwa hal-hal baik akan terjadi pada diri mereka. Para peserta juga menumbuhkan keyakinan bahwa sesuatu dapat berjalan sesuai dengan harapan mereka. Disisi lain, terjadi penurunan skor pada aspek pesimisme. Keyakinan para peserta bahwa hal buruk akan terjadi dimasa depan atau hal buruk akan menimpa mereka menjadi menurun.

Menurut Scheier dan Carver (dalam Synder \& Lopez, 2002), individu yang pesimis adalah individu yang memiliki keyakinan pesimis terhadap dirinya dan mengalami distorsi kognitif, sehingga mereka merasa bahwa mereka tidak dapat mencapai tujuan mereka. Keyakinan pesimis tersebut dapat diubah menjadi optimis melalui perubahan kognisi ke arah yang lebih positif. Faktor kognitif merupakan salah satu faktor pendukung optimisme. Keyakinan dan pikiran positif akan meningkatkan optimisme dan membuat individu memandang dirinya dan dunia dengan lebih positif. Terapi kognitif perilaku ditemukan dapat mengubah cara berpikir dari pesimis menjadi optimis (Synder \& Lopez, 2002).

Pada penelitian ini, para peserta tidak hanya mengembangkan keyakinan dan harapan yang lebih positif, namun juga melakukan usaha untuk mencapai harapanharapan tersebut. Tindak lanjut yang dilakukan setelah dua minggu pelatihan menunjukkan bahwa para peserta mempertahankan optimisme mereka. Ada peserta yang berusaha tidak bertindak impulsif ketika marah dengan teman, ada peserta yang dapat mempertahankan perilaku baik, dan ada juga peserta yang mulai memikirkan masa depan serta merencanakan pekerjaan yang ingin dilakukan setelah bebas. Berbeda dengan kelompok eksperimen yang mengalami peningkatan optimisme, subjek yang berada di kelompok kontrol tidak mengalami peningkatan skor total dan mean.

\section{SIMPULAN}

Berdasarkan hasil penelitian yang telah dilakukan oleh peneliti, berikut beberapa kesimpulan yang didapatkan, yakni pelatihan berpikir positif secara signifikan dapat meningkatkan optimisme anak binaan di LPKA. Anak binaan yang mengikuti pelatihan menjadi yakin dan berharap bahwa mereka dapat memiliki masa depan yang lebih baik dan yakin bahwa hal-hal baik dapat terjadi. Para peserta juga menjadi tidak terlalu yakin bahwa hal buruk akan menimpa mereka. Pelatihan berpikir positif secara signifikan efektif dalam meingkatkan optimisme selama dua minggu setelah pelatihan diadakan. Kelompok kontrol yang tidak mendapatkan pelatihan berpikir positif tidak mengalami peningkatan skor optimisme.

\section{SARAN}

Ada beberapa saran yang penulis hendak sampaikan. Pertama, saran untuk peneliti selanjutnya. Peneliti selanjutnya dapat menambahkan metode sharing untuk penggalian masalah pada tahap awal pelatihan. Peneliti selanjutnya juga diharapkan dapat memberikan tugas rumah kepada peserta dengan cara yang kreatif karena anak binaan tidak boleh memiliki alat tulis.

Kedua, saran untuk peserta. Para peserta diharapkan dapat terus mengingat materi pelatihan berpikir positif dan terus mempraktikkan berpikir positif dalam segala aspek kehidupan sehari-hari. Peserta juga diharapkan meningkatkan rasa optimis terhadap diri dan masa depan. Dengan meningkatkan rasa optimis, peserta akan mampu menjalani masa hukuman dengan lebih baik. Peserta diharapkan mengikuti berbagai kegiatan positif dan pelatihan yang diadakan di LPKA.

Ketiga, saran untuk LPKA Kelas 1 Kutoarjo. LPKA Kelas 1 Kutoarjo diharapkan dapat memberikan konseling individu bagi anak binaan yang membutuhkan. Anak binaan perlu 
diberikan keterampilan manajemen resiko, agar mengurangi kecenderungan menjadi residivis di kemudian hari. Kemudian, dengan adanya kasus persetubuhan yang paling banyak di LPKA, adanya pendidikan seksual menjadi hal penting agar anak didik memahami perilaku seksual yang baik dan benar.

\section{DAFTAR PUSTAKA}

Ariyanto, E. A. (2016). Tingkat stres pada remaja di lapas anak Blitar. Persona, Jurnal Psikologi Indonesia, 5(03), 226-231.

Aulia, P. (2017). Terapi kelompok untuk mengurangi stres anak didik pemasyarakatan yang akan bebas. Jurnal RAP UNP, 8(1), 69-78.

Ginneken, E. V. (2015). The role of hope in preparation for release from prison. Prison Service Journal, 220(10), 1015.

Halim, D. (2019, Januari 8). Kasus anak berhadapan dengan hukum tertinggi, didominasi kejahatan seksual. Kompas.com.https://nasional.kompas. com/read/2019/01/08/19381211/kasus -anak-berhadapan-dengan-hukumtertinggi-didominasi-kejahatanseksual.

Hilman, D, P., \& Indrawati, S, E. (2017). Pengalaman menjadi narapidana remaja di lapas kelas I Semarang. Jurnal Empati, 7(3), 189-203.

Kumar, S. (2019). Shifting epistemology of juvenile justice in India. Contexto Internacional, 41(1), 113-140.

Moore, K, E., Stuewig, J, B., \& Tangney, J, P. (2016). The effect of stigma on criminal offenders functioning: A longitudinal mediational model. Deviant Behavior, 37(2), 196-218.
Munawaroh, E., Isrofin, B., \& Sutikno, U, G. (2018). Konseling ABCDE Seligman untuk meningkatkan optimisme mahasiswa pindah jurusan. Jurnal Psikoedukasi dan Konseling, 2(2), 53-58.

National Research Council Institute of Medicine. (2001). Juvenile crime, juvenile justice. (https://www.nap.edu/read/9747/chapt er/3\#22.

Nurindah, M., Afiatin, T., \& Sulistyarini, I. (2012). Meningkatkan optimisme remaja panti sosial dengan pelatihan berpikir positif. Jurnal Intervensi Psikologi, 4(1), 57-76.

Nwokeoma, B. N., Ede, M. O., Ugwuanyi, C., Mezieobi, D., Ugwoezuonu, A. U., Amoke, C., Egenti, N. T., Nwosu, N., Oforka, T. O., Victor-Aigbodion, V., Offordile, E. E., Ezeh, N. E., Eze, C. O., Eluu, P. E., Ugwuanyi, B. E., Uzoagba, N. C., Ugwonna, G. O., Chukwu, C. L., Amadi, K. C., \& Eseadi, C. (2019). Efficacy of prisonbased cognitive behavioral rehabilitation intervention on violent sexual behaviors among sex offenders in Nigerian prisons. Medicine, 98(29), e16103.

doi: https://doi.org/10.1097/MD.00000000 00016103.

Peale, N. V. (1996). Berpikir positif. Binarupa Aksara.

Peterson, C. (2000). The future of optimism. American Psychologist, 55(1), 44-55.

Scheier, M., \& Carver, C. (1985). Optimism, coping, and health: Assessment and implication of generalized outcome expectancies. Health Psychology, 4(3), 219-247. 
Seligman, M. E. P. (2006). Learned optimism: How to change your mind and your life. Alfred A. Knof Publisher.

Shagufta, S., Boduszek, D., Dhingra, K., Palmer, D, K. (2015). Criminal social identity and suicide ideation among Pakistani young prisoners. International Journal of Prisoner Health, 11(2), 98-107.

Sholichatun, Y. (2011). Stres dan strategi coping pada anak didik di lembaga pemasyarakatan anak. Psikoislamika, $8(1), 23-42$.

Snyder, C.R., \& Lopez, S.J. (2002). Handbook of positive psychology. Oxford University Press.

Sopiah, N., Krisnatuti, D., \& Simanjuntak, M. (2017). Kerentanan, strategi coping, dan penyesuaian anak di Lembaga Pembinaan Khusus Anak (LPKA). Jurnal Ilmu Keluarga dan Konsumen, 10(3), 192-203.
Tatara, B.A. (2017). Efektivitas pelatihan berpikir positif untuk meningkatkan optimisme penyalahguna narkotika di Balai Rehabilitasi BNN Tanah Merah Samarinda [Tesis Tidak Diterbitkan]. Fakultas Psikologi Universitas Katolik Soegijapranata Semarang.

Yusuf, Y., Mufarida, B., Purnama, R.R., Rochim, A. (2019, Maret 14). Tindak kriminalitas anak sangat memprihatinkan. Sindonews.com. https://nasional.sindonews.com/read/1 386542/13/tindak-kriminalitas-anaksangat memprihatinkan-1552524624.

Zulni, L., \& Koentjoro. (2017). Pelatihan berpikir positif untuk menurunkan kecemasan menghadapi masa bebas pada anak di lembaga pembinaan khusus anak Kutoarjo. Gadjah Mada Journal of Professional Psychology, 3(1), 14-22. 